Case Report

\title{
Isolated p.H62L Mutation in the CYP21A2 Gene in a Simple Virilizing 21-Hydroxylase Deficient Patient
}

\author{
Melisa Taboas, ${ }^{1,2}$ Cecilia Fernández, ${ }^{1}$ Susana Belli, ${ }^{3}$ Noemi Buzzalino, ${ }^{1}$ \\ Liliana Alba, ${ }^{1}$ and Liliana Dain ${ }^{1,2}$ \\ ${ }^{1}$ Centro Nacional de Genètica Médica, ANLIS “Dr. Carlos G. Malbrán”, Buenos Aires, Argentina \\ ${ }^{2}$ Instituto de Biologia y Medicina Experimetal, CONICET, Buenos Aires, Argentina \\ ${ }^{3}$ Divisiòn Endocrinología, Hospital Durand, Buenos Aires, Argentina \\ Correspondence should be addressed to Liliana Dain; ldain@fbmc.fcen.uba.ar
}

Received 13 May 2013; Accepted 15 June 2013

Academic Editors: M. Fenger, S. F. Grant, and G. Vogt

Copyright (C) 2013 Melisa Taboas et al. This is an open access article distributed under the Creative Commons Attribution License, which permits unrestricted use, distribution, and reproduction in any medium, provided the original work is properly cited.

\begin{abstract}
Congenital adrenal hyperplasia due to 21-hydroxylase deficiency accounts for $90 \%-95 \%$ of cases. This autosomal recessive disorder has a broad spectrum of clinical forms, ranging from severe or classical, which includes the salt-wasting and simple virilizing forms, to the mild late onset or nonclassical form. Most of the disease-causing mutations described are likely to be the consequence of nonhomologous recombination or gene conversion events between the active CYP21A2 gene and its homologous CYP21A1P pseudogene. Nevertheless, an increasing number of naturally occurring mutations have been found. The change p.H62L is one of the most frequent rare mutations of the CYP21A2 gene. It was suggested that the p.H62L represents a mild mutation that may be responsible for a more severe enzymatic impairment when presented with another mild mutation on the same allele. In this report, a 20 -year-old woman carrying an isolated p.H62L mutation in compound heterozygosity with c.283-13A/C>G mutation is described. Although a mildly nonclassical phenotype was expected, clinical signs and hormonal profile of the patient are consistent with a more severe simple virilizing form of 21-hydroxylase deficiency. The study of genotype-phenotype correlation in additional patients would help in defining the role of p.H62L in disease manifestation.
\end{abstract}

\section{Introduction}

Congenital adrenal hyperplasia (CAH) due to 21-hydroxylase deficiency (OMIM 201910) accounts for 90\%-95\% of CAH cases $[1,2]$. This autosomal recessive disorder, which is the most frequent inborn error of metabolism, has a broad spectrum of clinical forms, ranging from severe or classical, which includes the salt-wasting (SW) and simple virilizing (SV) forms, to the mild late onset or nonclassical form of CAH (NCCAH) [1].

The affected enzyme, P450C21, is encoded by the CYP21A2 gene, located together with a $98 \%$ nucleotide sequence identity CYP21A1P pseudogene, on chromosome $6 \mathrm{p} 21.3$. Due to the high degree of identity between this gene and its pseudogene, most of the disease-causing mutations described are likely to be the consequence of nonhomologous recombination or gene conversion events $[3,4]$. In addition, more than 130 rare point mutations that arise independently of the pseudogene and that were found specific to a population or a single family, have been described to date (for details visit http://www.hgmd.cf.ac.uk). Most of the patients are compound heterozygotes and their phenotype depends on the underlying combination of mutations they have [5].

The change p.H62L is one of the most frequent rare mutations of the CYP21A2 gene. Based on patients' phenotypes and functional studies, it has been proposed that the p.H62L allele represents a mild mutation, which may be responsible for a more severe phenotype only when associated with another mild mutation on the same allele $[6,7]$. Moreover, by in silico analyses using as a template the crystallized bovine CYP21 that shares $79 \%$ sequence identity with the human CYP21A2 protein, Haider et al. (2013) associate this mutation to the mild form of the disease [8].

Herein we describe a recently genotyped patient from our cohort carrying an isolated p.H62L mutation in one allele and the severe c.283-13A/C>G mutation in the other 
one. Although a mild NCCAH phenotype was expected, the patient presents a classical SV form of the disease.

\section{Case Report}

2.1. Clinical and Hormonal Evaluations. Endocrine and genetic evaluations were conducted at the Division Endocrinología of the Hospital Durand and at the Centro Nacional de Genética Médica, Buenos Aires, Argentina. Patient was included following the diagnostic criteria already described $[9,10]$. 17-Hydroxyprogesterone (17OHP), androstenedione $\left(\mathrm{A}_{4}\right)$, and testosterone $(\mathrm{T})$ were assayed by radioimmunoassay (RIA) using a commercial kit from Diagnostic System Laboratory (DSL), Houston, TX, USA. Plasma Renin Activity (PRA) was measured using a commercial kit from Renin, BioChem Immuno System, Rome, Italy (MAIA), as previously described $[9,10]$.

The patient, a 20 year-old woman, was referred from the paediatric unit for ongoing management of simple virilising form of congenital adrenal hyperplasia due to 21-hydroxylase deficiency. She presented genital ambiguity with almost complete labial fusion and clitoromegaly since birth; however medical attention was achieved at the age of 3.5 years. She presented a single urogenital orifice and a $2.4 \mathrm{~cm}$ clitoris with phallic appearance and no palpable gonads, advanced bone age of 5.3 years old, and $1.04 \mathrm{~m}$ height (P90-97). Plasmatic levels of $17 \alpha$-hydroxyprogesterone were $>66 \mathrm{nmol} / \mathrm{L}$ (absolute values of the hormone in diluted sera were not available). She also presented increased plasma rennin activity of $9.5 \mathrm{ng} / \mathrm{mL} / \mathrm{h}$ (normal values $0.15-2.33$ ). She received oral hydrocortisone and $9 \alpha$-fludrocortisone $(0.05 \mathrm{mg}$ per day). At age of 6 , the patient underwent successful genital reconstruction with clitoral reduction and flap vaginoplasty. She had menarche at age 10.8 and regular menses since then. Due to adequate treatment compliance, she achieved a $1.55 \mathrm{~m}$ final height and had satisfactory sexual intercourse since the age of 19 years. When transferred to adult unit, treatment diagram was switched to prednisone $3 \mathrm{mg}$ taken nightly. Given that basal plasma rennin activity was still increased $(7.1 \mathrm{ng} / \mathrm{mL} / \mathrm{h}), 9 \alpha$ - fludrocortisone treatment was kept. Under this treatment regimen, serum hormonal levels showed $17 \alpha$-hydroxyprogesterone $3.3 \mathrm{nmol} / \mathrm{mL}$, androstenedione $5.23 \mathrm{nmol} / \mathrm{mL}$, and total testosterone $1.11 \mathrm{nmol} / \mathrm{L}$.

2.2. Molecular Analyses. After written informed consent was obtained, DNA was isolated from peripheral blood leucocytes, and the 10 most frequent point mutations in the CYP21A2 gene were screened, following methodology previously established in our laboratory $[9,10]$. Briefly, CYP21A2 gene was specifically amplified by PCR in three overlapping fragments, and each mutation was screened by allele-specific PCR or PCR-RFLP in a second round of PCR using one of these previously amplified fragments as templates. Samples from patients who presented at least one nondetermined allele were further analyzed by direct sequencing covering the entire gene and proximal promoter regions of CYP21A2 in four gene-specific overlapping fragments as previously

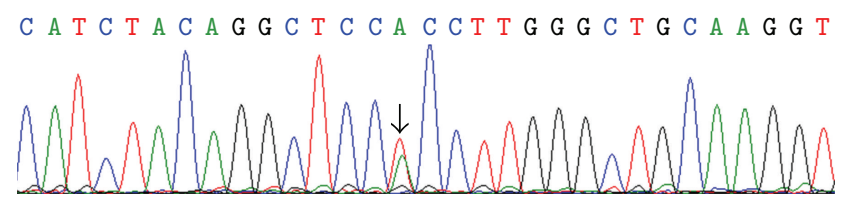

(a)

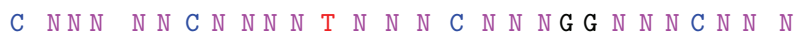

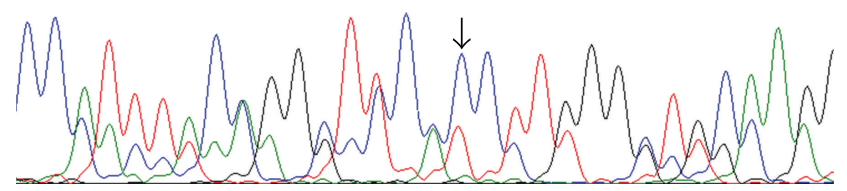

(b)

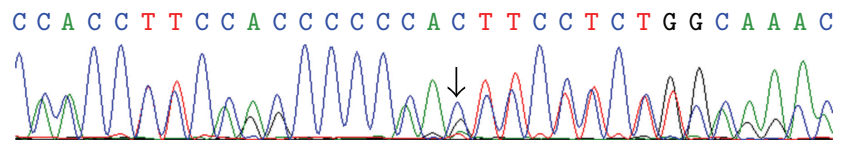

(c)

FIGURE 1: Representative electropherograms of the mutations found in the patient. The mutations are shown by arrows. (a) g.185A $>\mathrm{T}$ (p.H62L) mutation. (b) Reverse complement electropherogram showing the deduced presence of g.185A $>$ T (p.H62L) on the allele carrying the g.562_568delG polymorphism. (c) IVS2-13 A/C>G mutation on the homologous allele.

described [11]. In addition, two previously described regulatory regions $[12,13]$ were also analyzed by direct sequencing.

The combined strategy described above revealed the presence of c.283-13A/C $>$ G and g.185A $>$ T (p.H62L) mutations, both in heterozygosis (Figures 1(a) and 1(c)). Even though the parents were not available, the presence of $6 \mathrm{G}$ or $7 \mathrm{G}$ at a polymorphic site in intron 2 (g.562_568delG) allowed the identification of both mutations localized in trans (Figure 1(b)). In addition, the patient presented 3 polymorphic variants in heterozygosis: g.692A $>$ G (p.K102R) in exon 3, g.1130C > G (p.D183E) in exon 5, and g.2702A $>$ G (p.N493S) in exon 10, thus further excluding a putative allele dropout commonly found in CYP21A2 gene amplifications [14]. No variations were found in the regulatory regions analyzed.

\section{Discussion}

The adrenocortical 21-hydroxylase is one of the key enzymes in glucocorticoid and mineralocorticoid biosynthesis. Mutations in the CYP21A2 gene have been reported in individuals affected with $\mathrm{CAH}$ due to 21-hydroxylase deficiency. To date, a great number of different mutations in the CYP $21 A 2$ gene have been described. Because $\mathrm{CAH}$ is a recessive disorder and most of the 21-hydroxylase deficient patients are compound heterozygotes with different mutations in both alleles, their phenotype depends on the underlying combination of mutations they have [5]. Even though most patients carry CYP21A1P-derived mutations, an increasing number of naturally occurring mutations have been found in disease-causing alleles in the last years. 
The change p.H62L is one of the most frequent rare mutations of the CYP21A2 gene. To date, thirty-one 21hydroxylase deficient patients have been reported carrying the non-derived-pseudogene p.H62L mutation [6, 7, 15-19]. Most of them presented a second mutation on the same allele, while only twelve patients ( 7 of the Taiwanese population) from among all the reported in bibliography showed no additional mutations in cis $[6,15,17,18]$.

By in silico analyses, a recent report predicts that the substitution of histidine by hydrophobic leucine may disrupt hydrogen bonding between H62 and G35 to reduce, but not eliminate, enzyme activity [8]. While functional assays also suggested that p.H62L is a mild mutation, presence of another mutation on the same allele disclosed a synergistic effect in reducing enzyme activity $[6,7]$.

We herein report a classical patient who presents an isolated p.H62L in one allele and the c.283-13A/C > G mutations in the other one. Unlike the mild phenotype found in those patients previously described with the isolated p.H62L mutation in compound heterozygosity with a severe one, clinical manifestations and hormonal profile of the patient herein described are consistent with a SV form of the disease. More severe clinical manifestations of the disease were found, by contrast, in those patients carrying p.H62L with another mild mutation on the same allele $[6,7]$. Though the entire gene and promoter regions were sequenced in the DNA sample from the patient from our cohort, no additional mutations were found. No variations were either found when we analyzed, by direct sequencing, two previously described regulatory regions. Nevertheless, it should be noted that the patient reported in 2009 in Japan, who presented an isolated p.H62L in one allele and the severe cluster E6 (p.I236M, p.V237 E, p.M239 K) mutation in the other one, disclosed an intermediate phenotype. She presented clitoral size at the upper limit for normal and 17-OHP levels between the SV and NCCAH forms [17].

Discordances between genotype and phenotype in 21hydroxylase deficiency have already been described in previous reports. Indeed, a recent work by New et al. [20] found a direct genotype-phenotype correlation in less than $50 \%$ of the genotypes studied. All these observations as a whole may suggest that despite mildly impaired enzymatic activity of the isolated p.H62L variable suggested by in vitro functional studies, presence of other genetic or environmental factors may contribute to modulate the activity of the enzyme in vivo.

The study of genotype-phenotype correlation in additional patients presenting this mutation would help in defining the role of this variable in disease manifestation. In the meantime, the possibility that p.H62L mutation by itself may be associated with a more severe clinical form of 21hydroxylase deficiency should be considered.

\section{Conflicts of Interests}

The authors declare that there is no conflict of interests that could be perceived as prejudicing the impartiality of the research reported.

\section{Acknowledgments}

The authors thank Dr. V. Sundblad, for helpful revision of the paper. This work was supported by Grants from the ANPCYT: PICT 2006-00208, UBACYT X059, and Roemmers Foundation. M. Taboas is a fellow from the Consejo Nacional de Investigaciones Científicas y Tecnológicas (CONICET).

\section{References}

[1] M. I. New, P. C. White, S. Pang, B. Dupont, and P. W. Speiser, "The adrenal hyperplasias," in The Metabolic Basis of Inherited Disease, C. R. Scriver, A. L. Beaudet, S. Sly, and D. Valle, Eds., vol. 2, pp. 1881-1917, McGraw-Hill, New York, NY, USA, 1989.

[2] W. L. Miller, "Clinical review 54: genetics, diagnosis, and management of 21-hydroxylase deficiency," Journal of Clinical Endocrinology and Metabolism, vol. 78, no. 2, pp. 241-246, 1994.

[3] P. A. Donohoue, C. Van Dop, and R. H. McLean, "Gene conversion in salt-losing congenital adrenal hyperplasia with absent complement C4B protein," Journal of Clinical Endocrinology and Metabolism, vol. 62, no. 5, pp. 995-1002, 1986.

[4] Y. Higashi, A. Tanae, H. Inoue, and Y. Fujii-Kuriyama, "Evidence for frequent gene conversion in the steroid 21hydroxylase P-450 (C21) gene: implications for steroid 21hydroxylase deficiency," American Journal of Human Genetics, vol. 42, no. 1, pp. 17-25, 1988.

[5] P. C. White and P. W. Speiser, "Congenital adrenal hyperplasia due to 21-hydroxylase deficiency," Endocrine Reviews, vol. 21, no. 3, pp. 245-291, 2000.

[6] R. Menassa, V. Tardy, F. Despert et al., "p.H62L, a rare mutation of the CYP21 gene identified in two forms of 21-hydroxylase deficiency," Journal of Clinical Endocrinology and Metabolism, vol. 93, no. 5, pp. 1901-1908, 2008.

[7] F. C. Soardi, M. Barbaro, I. F. Lau et al., "Inhibition of CYP21A2 enzyme activity caused by novel missense mutations identified in brazilian and scandinavian patients," Journal of Clinical Endocrinology and Metabolism, vol. 93, no. 6, pp. 2416-2420, 2008.

[8] S. Haider, B. Islam, V. D’Atri et al., "Structure-phenotype correlations of human CYP21A2 mutations in congenital adrenal hyperplasia," Proceedings of the National Academy of Sciences of the United States of America, vol. 110, no. 7, pp. 2605-2610, 2013.

[9] L. B. Dain, N. D. Buzzalino, A. Oneto et al., "Classical and nonclassical 21-hydroxylase deficiency: a molecular study of Argentine patients," Clinical Endocrinology, vol. 56, no. 2, pp. 239-245, 2002.

[10] T. Pasqualini, G. Alonso, R. Tomasini et al., "Congenital adrenal hyperplasia. Clinical characteristics and genotype in newborn, childhood and adolescence," Medicina, vol. 67, no. 3, pp. 253261, 2007.

[11] C. Minutolo, A. D. Nadra, C. Fernández et al., "Structurebased analysis of five novel disease-causing mutations in 21hydroxylase-deficient patients," PLoS ONE, vol. 6, no. 1, Article ID e15899, 2011.

[12] N. Watanabe, M. Kitazume, J. Fujisawa, M. Yoshida, and Y. Fujii-Kuriyama, "A novel cAMP-dependent regulatory region including a sequence like the cAMP-responsive element, far upstream of the human CYP21A2 gene," European Journal of Biochemistry, vol. 214, no. 2, pp. 521-531, 1993. 
[13] S. D. Wijesuriya, G. Zhang, A. Dardis, and W. L. Miller, "Transcriptional regulatory elements of the human gene for cytochrome P450c21 (steroid 21-hydroxylase) lie within intron 35 of the linked C4B gene," Journal of Biological Chemistry, vol. 274, no. 53, pp. 38097-38106, 1999.

[14] D. J. Day, P. W. Speiser, E. Schulze et al., "Identification of non-amplifying CYP21 genes when using PCR-based diagnosis of 21-hydroxylase deficiency in congenital adrenal hyperplasia (CAH) affected pedigrees," Human Molecular Genetics, vol. 5, no. 12, pp. 2039-2048, 1996.

[15] B. Ezquieta, E. Cueva, J. Varela, A. Oliver, J. Fernández, and C. Jariego, "Non-classical 21-hydroxylase deficiency in children: association of adrenocorticotropic hormone-stimulated 17hydroxyprogesterone with the risk of compound heterozygosity with severe mutations," Acta Paediatrica, vol. 91, no. 8, pp. 892898, 2002.

[16] F. B. Coeli, F. C. Soardi, R. D. Bernardi et al., "Novel deletion alleles carrying CYP21A1P/A2 chimeric genes in Brazilian patients with 21-hydroxylase deficiency," BMC Medical Genetics, vol. 11, no. 1, article 104, 2010.

[17] K. Nagasaki, T. Usui, T. Asami, Y. Ogawa, T. Kikuchi, and M. Uchiyama, "H62L mutation of CYP21A2 identified in the nonclassical form of 21-hydroxylase deficiency," Clinical Pediatric Endocrinology, vol. 18, no. 4, pp. 111-113, 2009.

[18] S.-F. Chang and H.-H. Lee, "Analysis of the CYP21A2 gene with intergenic recombination and multiple gene deletions in the RCCX module," Genetic Testing and Molecular Biomarkers, vol. 15, no. 1-2, pp. 35-42, 2011.

[19] N. Krone, I. Rose, D. Willis et al., "Genotype-phenotype correlation in 153 adult patients with congenital adrenal hyperplasia due to 21-hydroxylase deficiency: analysis of the United Kingdom Congenital adrenal Hyperplasia Adult Study Executive (CaHASE) cohort," The Journal of Clinical Endocrinology \& Metabolism, vol. 98, pp. 346-354, 2013.

[20] M. I. New, M. Abraham, B. Gonzalez et al., "Genotypephenotype correlation in 1,507 families with congenital adrenal hyperplasia owing to 21-hydroxylase deficiency," Proceedings of the National Academy of Sciences of the United States of America, vol. 110, no. 7, pp. 2611-2616, 2013. 


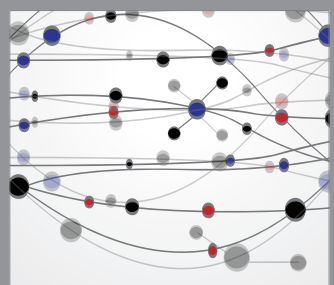

The Scientific World Journal
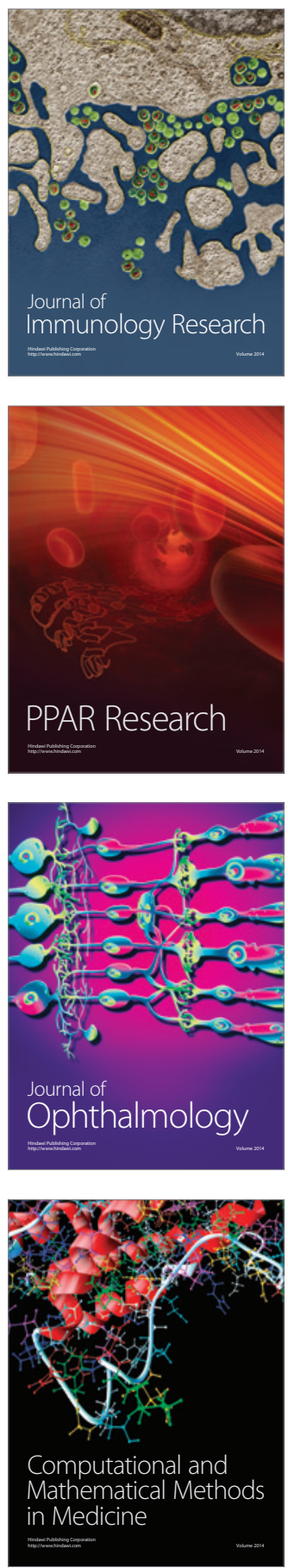

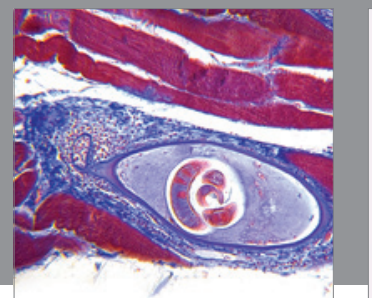

Gastroenterology

Research and Practice
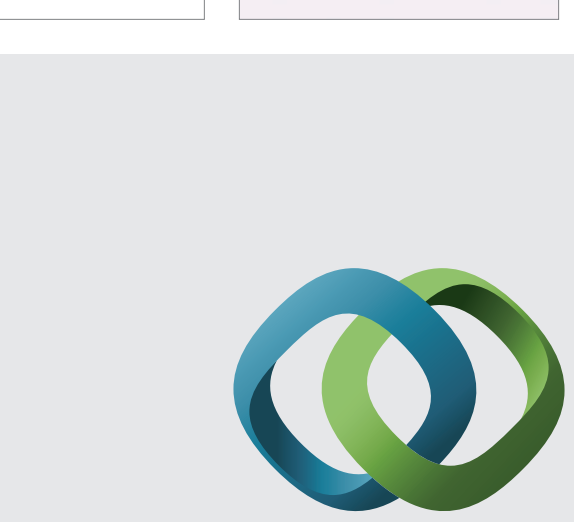

\section{Hindawi}

Submit your manuscripts at

http://www.hindawi.com
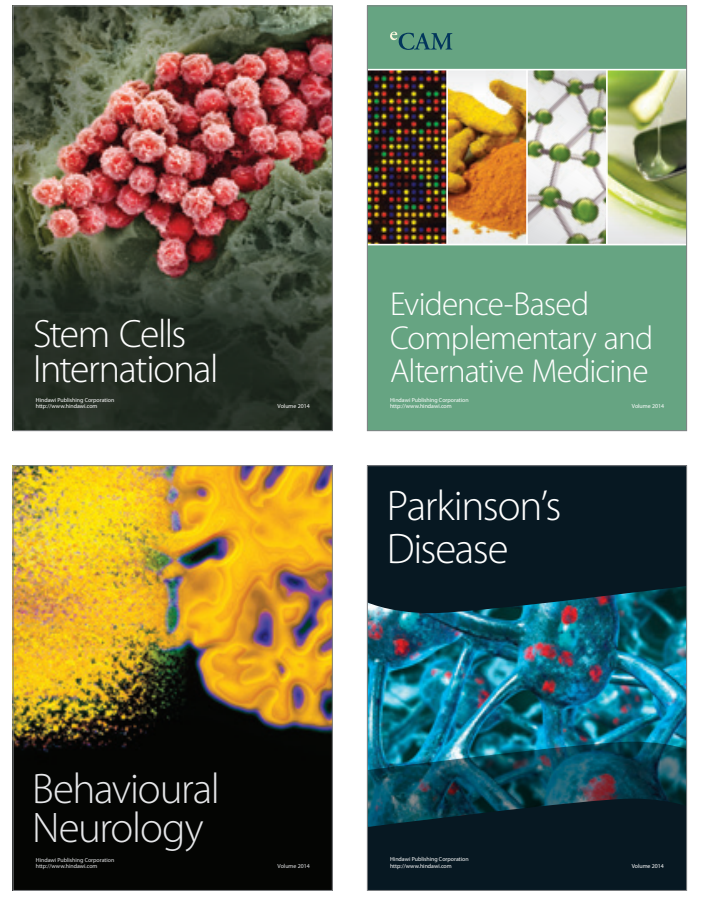
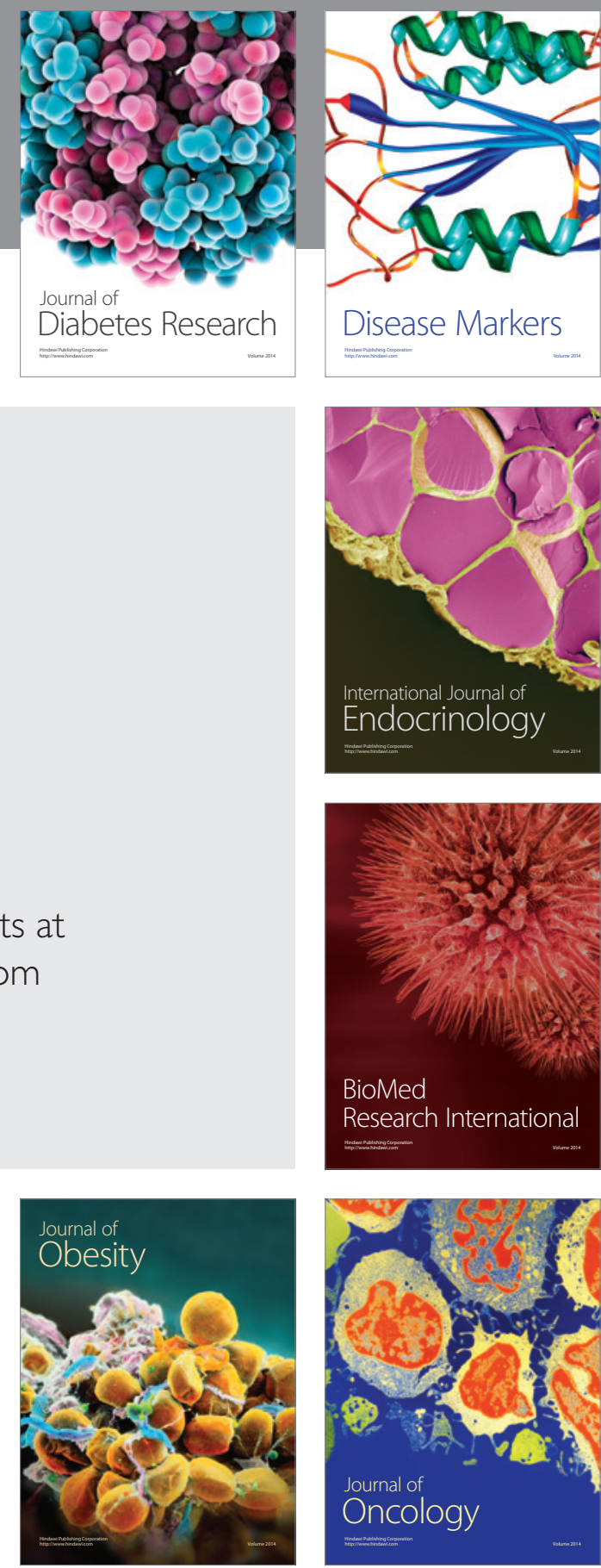

Disease Markers
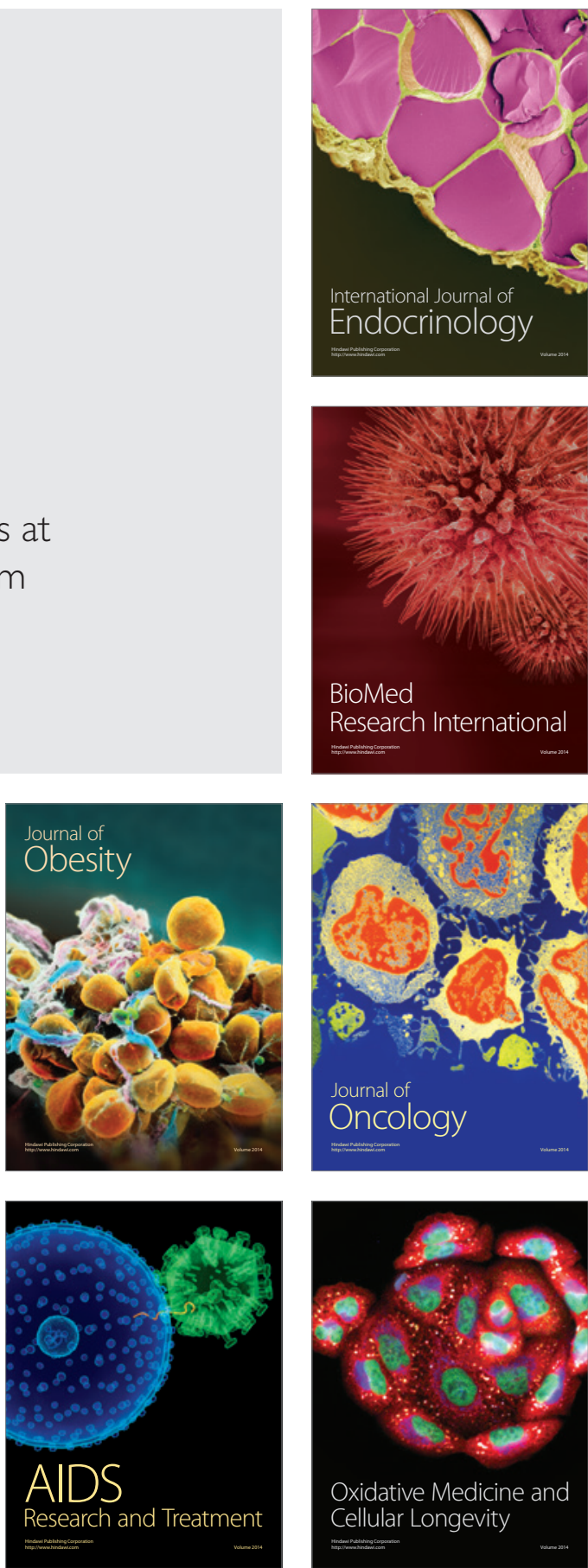